\title{
Additions to the phylogeny of colubrine snakes in Southwestern Asia, with description of a new genus and species (Serpentes: Colubridae: Colubrinae)
}

\author{
Mahdi Rajabizadeh ${ }^{\mathrm{C}}$ \\ ${ }^{6}$, Anthony Herrel ${ }^{2,6,7}$ \\ R. Alexander Pyron ${ }^{3}$, Roman Nazarov ${ }^{\text {Corresp., } 4}{ }^{2}$ Nikolay A Poyarkov ${ }^{5}$, Dominique Adriaens \\ ${ }^{1}$ Department of Biodiversity, Institute of Science and High Technology and Environmental Sciences, Kerman, Iran \\ 2 Département 'Adaptations du vivant', Museum national d'Histoire naturelle, Paris, France \\ 3 Department of Biological Sciences, the George Washington University, Washington DC, United States \\ ${ }^{4}$ Zoological Museum, Moscow State University, Moscow, Russia \\ 5 Department of Vertebrate Zoology, Faculty of Biology, Moscow State University, Moscow, Russia \\ ${ }^{6}$ Department of Biology, Evolutionary Morphology of Vertebrates, Ghent University, Ghent, Belgium \\ 7 Department of Biology, Functional Morphology, University of Antwerp, Antwerp, Belgium \\ Corresponding Authors: Mahdi Rajabizadeh, Roman Nazarov \\ Email address: khosro.rajabizadeh@gmail.com, r_nazarov@mail.ru \\ Reptiles are still being described worldwide at a pace of hundreds of species a year. While \\ many discoveries are from remote tropical areas, biodiverse arid regions still harbor many \\ novel taxa. Here, we present an updated phylogeny of colubrid snakes from the Western \\ Palearctic by analyzing a supermatrix of all available global snake species with molecular \\ data and report on the discovery of a new genus and species of colubrine snake from \\ southeastern Iran. The new taxon, named Persiophis fahimii Gen. et sp. nov., is nested \\ within a clade containing Middle Eastern and South Asian ground racers (Lytorhynchus, \\ Rhynchocalamus, Wallaceophis, and Wallophis). This species has a derived morphology \\ including an edentulous pterygoid and occurrence of short and blunt teeth on the palatine, \\ maxillae and dentary bones, an elongated snout and a relatively trihedral first supralabial \\ scale that is slightly bigger than the second, and elongated toward the tip of rostral. We \\ also report on the osteology and phylogenetic placement of several poorly studied \\ colubrines: Hierophis andreanus (reassigned to Dolichophis) and Muhtarophis barani.
}


1 Additions to the phylogeny of colubrine snakes in Southwestern

2 Asia, with description of a new genus and species (Serpentes:

3 Colubridae: Colubrinae)

5 Mahdi Rajabizadeh ${ }^{1,2^{*}}$, R. Alexander Pyron ${ }^{3}$, Roman A. Nazarov ${ }^{4 *}$, Nikolay A.

6 Poyarkov $^{5}$, Dominique Adriaens 6 , Anthony Herrel ${ }^{2,6,7}$

81 -Department of Biodiversity, Institute of Science and High Technology and Environmental

9 Sciences, Kerman, Iran

102 -Département 'Adaptations du vivant', Museum national d'Histoire naturelle, Paris, France

113 - Department of Biological Sciences, the George Washington University, Washington DC,

12 United States

134 -Zoological Museum, Moscow State University, Moscow, Russia

145 - Department of Vertebrate Zoology, Faculty of Biology, Moscow State University, Moscow,

$15 \quad$ Russia

16 - Ghent University, Department of Biology, Evolutionary Morphology of Vertebrates, Ghent,

17 Belgium

187 -University of Antwerp, Department of Biology, Functional Morphology, Antwerp, Belgium

19 *E-mails of corresponding authors: khosro.rajabizadeh@gmail.com; r_nazarov@mail.ru

RUNNING TITLE: A new snake genus from Iran

ABSTRACT 
Reptiles are still being described worldwide at a pace of hundreds of species a year. While many discoveries are from remote tropical areas, biodiverse arid regions still harbor many novel taxa. Here, we present an updated phylogeny of colubrid snakes from the Western Palearctic by analyzing a supermatrix of all available global snake species with molecular data and report on the discovery of a new genus and species of colubrine snake from southeastern Iran. The new taxon, named Persiophis fahimii Gen. et sp. nov., is nested within a clade containing Middle Eastern and South Asian ground racers (Lytorhynchus, Rhynchocalamus, Wallaceophis, and Wallophis). This species has a derived morphology including an edentulous pterygoid and occurrence of short and blunt teeth on the palatine, maxillae and dentary bones, an elongated snout and a relatively trihedral first supralabial scale that is slightly bigger than the second, and

elongated toward the tip of rostral. We also report on the osteology and phylogenetic placement of several poorly studied colubrines: Hierophis andreanus (reassigned to Dolichophis) and Muhtarophis barani.

SUBJECTS: Biodiversity, Biogeography, Evolutionary Studies, Taxonomy, Zoology 
2013). While at least 1,959 species of colubrid snakes have been described (Uetz et al., 2020), there are undoubtedly many new species remaining to be discovered. Colubrid phylogeny has been recently studied at higher levels (Lawson et al., 2005; Nagy et al., 2004; Pyron et al., 2011; Vidal et al., 2007; Zaher et al., 2019) and with species-level sampling (Figueroa et al., 2016; Pyron et al., 2013; Zheng \& Wiens, 2016), but many nodes remain poorly supported. One of the possible reasons is the absence of unsampled or undescribed taxa, hampering the estimation of a complete phylogeny (see Pyron et al., 2013). This emphasizes the importance of studying the biodiversity of colubrid snakes, not only from a conservation point of view (Böhm et al., 2013), but also to shed light on the phylogeny of the whole group.

In phylogenetics, extensive sampling may increase accuracy (Zwickl \& Hillis, 2002). New methods and data may help in studying the biodiversity of rare colubrids, whether it be the discovery of new species, or the placement of enigmatic taxa. Thus, densely-sampled supermatrices of all available gene sequences are desirable to improve phylogenetic estimations (Pyron et al., 2011), both to cement the placement of sampled species as well as the recognition of new taxa. Furthermore, integrative taxonomy can help in accommodating different data sources and provide new avenues for delimiting species using different organismal properties (Padial et al., 2010).

Of Western Palearctic colubrid snakes in southwestern Asia (including Iran and adjacent countries), the phylogenetic relationships of a considerable number of rare or narrowly endemic taxa are unknown (Rajabizadeh, 2018). Here, we present an updated phylogeny of colubrid snakes from the Western Palearctic by analyzing a supermatrix of all available global snake species (Figueroa et al., 2016). To this matrix, we have added data from two rare and poorly known species from Iran. The first is Andreas' Racer, Hierophis andreanus (Werner, 1917), an endemic colubrid snake from Iran with ambiguous phylogenetic placement (Figueroa et al., 
2016; Schätti \& Monsch, 2004), currently classified in the genus Hierophis (Wallach et al., 2014). The second is a previously unknown taxon, discovered by us during a 2008 field survey in southeastern Iran, which shows unique morphological adaptations and represents a new genus and species of colubrid snakes. In addition to the molecular phylogeny, we provide osteological data for consideration in taxonomic evaluations.

\section{MATERIALS AND METHODS}

\section{Nomenclatural acts}

The electronic version of this article in Portable Document Format (PDF) will represent a published work according to the International Commission on Zoological Nomenclature (ICZN), and hence the new names contained in the electronic version are effectively published under that Code from the electronic edition alone (see Articles 8.5-8.6 of the Code). This published work and the nomenclatural acts it contains have been registered in ZooBank, the online registration system for the ICZN. The ZooBank LSIDs (Life Science Identifiers) can be resolved and the associated information can be viewed through any standard web browser by appending the LSID to the prefix http://zoobank.org/. The LSID for this publication is as follows: urn:lsid:zoobank.org:pub:4EAACC14-8FC8-46B9-830C-4AEC8A42A562. The online version of this work is archived and available from the following digital repositories: PeerJ, PubMed Central and CLOCKSS.

\section{Specimen Collection}

During one month of fieldwork in southern and western Iran (Fig. 1) in May 2008, two specimens of rare colubrid snakes were collected by R. Nazarov and M. Rajabizadeh: a sample of Hierophis andreanus, and a specimen of Colubridae Gen. et sp. nov. superficially resembling 
96

snakes of the genera Rhynchocalamus or Lytorhynchus. Voucher specimens were preserved and deposited in the International Center for Science, High Technology and Environmental Sciences Herpetological Collection (ICSTZM), Kerman, Iran, along with tissue samples (muscle tissue, preserved in 100\% ethanol) for molecular phylogenetic analysis. The skulls of both specimens were examined using micro-CT scanning. Specimen information are as follows:

1. Hierophis andreanus, collected from around Darreh Shahr City, western Iran, Ilam Province (Fig. 1), preserved in 75\% ethanol and cataloged as ICSTZM.7H.1154.

2. Colubridae Gen. et sp. nov., ICSTZM.7H.1151, collected from around Orzueeyeh City, southern Iran, Kerman Province (Fig. 1), preserved in 75\% ethanol.

Field work, including collection of the samples and animals in the field, was performed outside of any protected area, in the framework of a project contract signed by International Center for Science, High Technology and Environmental Sciences, Kerman, Iran (contract number 1.87, issued at 11.04.2008). The contract grants permission to collect the reptile samples outside of any protected area administered by the Department of the Environment (specified in www.doe.ir), which need extra permissions. Specimen collection protocols and animal operations followed the Institutional Ethical Committee of International Center for Science, High Technology and Environmental Sciences, Kerman, Iran (certificate number 1.87-1).

\section{Molecular Phylogeny}

We used the species-level supermatrix from Figueroa et al. (2016), which is currently the largest such dataset available for snakes (A dataset comprising 1745 taxa representing 1652 snake species and 7 outgroup taxa, and 9523 base pairs from 10 loci, accessible in https://doi.org/10.1371/journal.pone.0161070.s002). First, we removed the chimeric representative of "Lytorhynchus diadema" and added several newly-sequenced specimens from this clade derived from recent publications (Table 1). For our two new samples, we then added 
120 sequences for the mitochondrial genes 12S, ND4, and CYTB (sequencing details as in Pyron et $121 a l ., 2011$ ), accessioned in GenBank (Table S1). For the new colubrid taxon, we also sequenced 122 the nuclear genes BDNF, CMOS, NT3, and RAG2 (accessions in Table S1).

We used the same partitioning and analytical strategy as Figueroa et al. (2016). With their model-partitions file (by gene and codon), we estimated the Maximum-Likelihood phylogeny using IQ-TREE (Nguyen et al., 2014), under a partitioned model (Chernomor et al., 2016) with the best partitioning scheme chosen by AIC (Kalyaanamoorthy et al., 2017) and support estimated using 1,000 ultra-fast bootstraps (Hoang et al., 2017) and the branch-specific SHL-aLRT statistic (Anisimova et al., 2011). Following recommendations from the developers of IQ-TREE and previous studies (Anisimova et al., 2011; Pyron et al., 2011), we interpret clades with UF $>95$ and SHL $>80$ to indicate strong support. While we re-estimated the entire snake phylogeny, we only report results from the clade of interest containing our focal taxa and other Western Palearctic Colubrids.

\section{Osteology}

The skull osteology of Hierophis andreanus was compared with that of closely related genera, including Hierophis (H. gemonensis - MNHN 1937-454) and H. viridiflavus - MNHN 1967-79, 1869-806), loaned from the Muséum national d'Histoire naturelle in Paris), Dolichophis and Eirenis from published reports (Hosseinian Yousefkhani \& Rajabizadeh, 2014; Mahlow et al., 2013). Additionally, we gathered novel osteological observations regarding Colubridae Gen. et sp. nov., for a thorough description of the new taxon. The micro-CT scans of the heads of two snake specimens were performed at the Centre for X-ray Tomography of Ghent University (Vlassenbroeck et al., 2007). The setup was a transmission head of a dual-head X-ray tube (Feinfocus FXE160.51) and an a-Siflat panel detector (PerkinElmer XRD 1620 CN3 CS). The focal spot size was $900 \mathrm{~nm}$ at a tube voltage of $130 \mathrm{kV}$ for high resolution. Number of 
144 projections and voxel size of the scanned specimen is presented in Table S2. Exposure time was 1452 seconds per projection, resulting in a $360^{\circ}$ output CT Scan. The raw data were processed and 146 reconstructed using the in-house CT software Octopus (http://www.octopusreconstruction.com) 147 (Vlassenbroeck et al., 2007) and rendered using Amira V. 5.4.1 (Mercury Systems of Visage 148 Imaging $\mathrm{GmbH}$ ). The CT-rendered images were color coded to distinguish separate ossified units, where stiff and rigidly interconnected bones were given a single color.

\section{External morphology and comparisons}

151

152

153

\section{列}

Morphological examination was performed following to Dowling (1951). Snout-vent length (SVL) and tail length (TailL) were measured using a body ruler; other measurements to the nearest $0.1 \mathrm{~mm}$ using a Mitutoyo digital caliper. Pileus length was measured as the maximum distance from tip of snout to posterior margin of parietals. Dorsal scales rows were counted at the level of one head length posterior to the head (anterior body), midbody and one head length anterior to the anus (posterior body). Comparative morphological data were extracted from the literature (Boulenger, 1898; Bourgeois, 1968; Broadley, 1994; Broeckhoven \& du Plessis, 2017; Chan-Ard et al., 2015; Chippaux \& Jackson, 2019; Das et al., 2019; Gans, 1954; Kardong, 1979; Kharin \& Akulenko, 2008; Mahlow et al., 2013; Marx, 1959; Mirza \& Patel, 2018; Mirza et al., 2016; Nguyen et al., 2020; Poyarkov et al., 2019; Rajabizadeh, 2018; Saleh \& Sarhan, 2016; Schätti, 1985, 1987; Tsai \& Mao, 2017; Utiger et al., 2005; Wade, 2008; Wagner \& Böhme, 2007; Wallach et al., 2010; Wang et al., 2019).

\section{RESULTS}

\section{Phylogeny}

The ML tree (see Fig. 2) is overall highly similar to many recent estimates of colubroid 
168

169

170

171

172

173

174

175

176

snake phylogeny (Figueroa et al., 2016; Pyron et al., 2011; Zaher et al., 2019), with a few major exceptions highlighted in part by our new sampling. Our results confirm the occurrence of a monophyletic group $(\mathrm{UF} / \mathrm{SHL}=93 / 97)$ of Western Palearctic colubrids including 17 genera and Colubridae Gen. et sp. nov. However, phylogenetic placement of all genera within this clade is not fully resolved, due to low support values for some nodes. Our results strongly support a sister-group relationship of Muhtarophis barani and Scaphiophis albopunctatus (83/97), which together form a clade that is the sister group to all above mentioned genera of Western Palearctic and South Asian colubrids with high support (-/95). There are two main subclades of western Palearctic and South Asian colubrines that we highlight for further attention.

The first involves a small radiation of colubrine ground-snakes endemic to southwestern Asia (including Colubridae Gen. et sp. nov.), and the second involves colubrines from the OldWorld racer lineage. The first subclade is strongly supported (100/100), and includes Colubridae Gen. et sp. nov. as the sister lineage to a weakly supported clade containing Rhynchocalamus, Wallophis + Wallaceophis, and Lytorhynchus. The monophyly or sister relationship of each of those genera is strongly supported by at least one measure. However. the phylogenetic relationships between the latter genera are only moderately supported (85/70 and 75/68). The genetic distance of the new colubrid lineage from the remaining taxa combined with its morphological distinctiveness necessitates a novel generic assignment.

The second sub-clade is divided into several groups. In the first lineage, Mopanveldophis zebrinus is the sister group (89/100) to the genera Bamanophis and Macroprotodon. This lineage is sister to other remaining genera in the Western Palearctic colubrine clade $(100 / 100)$. The second lineage contains Hemorrhois as the sister group to the genera Spalerosophis and Platyceps with strong support (98/100). Relationships in the latter genus are poorly resolved (Fig. 2). We also note that recent cranial osteological and molecular phylogenetic data from 
192 Argyrogena fasciolata place it as the sister lineage of Platyceps (Das et al., 2019) in this clade.

193

194

195

196

197

198

199

200

201

202

203

204

205

206

207

208

209

210

211

212

213

214

215

Among the remaining lineages, the Western Palearctic whip snakes (genera Hierophis and Dolichophis), the Slender Racer (Orientocoluber), Hierophis andreanus, and dwarf snakes of the genus Eirenis are confirmed in our tree as a monophyletic group (100/100). The genus Hemerophis is weakly supported as the sister lineage to this entire clade. The clade comprises one lineage including the genera Orientocoluber and Hierophis (sister relationship strongly supported; 98/100), and a second lineage including the genera Dolichophis and Eirenis. Although the monophyly of each of the latter genera is confirmed, their sister group relationship is not supported by UF, only SHL (99). Furthermore, Hierophis andreanus is placed within the genus Dolichophis as the sister group to D. jugularis with strong support (91/98), and we thus formally reassign $H$. andreanus to Dolichophis. Based on our tree, monophyly of the genus Dolichophis is confirmed (100/100), with a basal divergence within the genus between a subgroup comprising D. schmidti and D. caspius (100/100), and another sub-group of D. jugularis and Dolichophis andreanus comb. nov.

\section{Systematics}

Phylogenetic results indicate that Colubridae Gen. et sp. nov. is nested within the subfamily Colubrinae, and we estimate moderate support for a sister group relationship with clade including snakes of the genera Rhynchocalamus, Wallophis, Wallaceophis, and Lytorhynchus. The Colubridae Gen. et sp. nov. is thus distantly diverged from all other colubrid snakes for which sequence data is available. From an osteological point of view, Colubridae Gen. et sp. nov. lacks teeth on the premaxilla and proteroglyphous or solenoglyphous teeth on the maxilla, a coronoid bone in the mandible, girdle or limb elements, and valvular dorsal nostrils (see Osteology, below), what confirms its assignment to the family Colubridae (Vitt \& Caldwell, 
216 2013). The occurrence of a broad articulation between snout bones and the lack of numerous and

217 closely-set teeth, as well as the fact that the specimen was found on an arid mountain side and 218 does not have an aquatic or semiaquatic lifestyle confirms that Colubridae Gen. et sp. nov. 219 belongs to the subfamily Colubrinae rather than the related subfamily Natricinae (Vitt \& 220 Caldwell, 2013; Zaher et al., 2012). Although the occurrence of an edentulous pterygoid is 221 observed in the genera Dasypeltis, Lytorhynchus and Rhynchocalamus as well (Avcr et al., 2015; 222 Gans, 1952, 1954; Leviton \& Anderson, 1970), the combination of osteological traits of 223 Colubridae Gen. et sp. nov. is unique within the subfamily, indicating that this single specimen

224 225 226

227

228 229

230

231

232

233

234 235

236

237 238 239

\section{Persiophis fahimii Gen. et sp. nov.}

(Figs. 3-5 and S1) represents a new genus as well as a new species of colubrid snakes, which are described herein as follows:

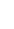

Holotype. Adult female, ICSTZM.7H.1151 (field number: RAN 2948). Iran, Kerman province, 19 km NW of Orzueeyeh City, 1350 meters ASL; coll. R. Nazarov, May 2008 (Figs. 35 and S1). The specimen originally preserved in $96 \%$ ethanol and then moved to $75 \%$ ethanol for long term preservation. Since the authors are concerned about the conservation of the species, the exact geographic coordinates of the type locality are not given herein, but can be obtained upon request from the authors.

Etymology. The genus name is a latinized noun in masculine gender derived from the Greek words "Persi-" (Persís) $=$ Persia (old name of Iran) and "ophis" = serpent. The species is named after Dr. Hadi Fahimi, a young naturalist and herpetologist who dedicated his life to studying the biodiversity and conservation of reptiles and mammals of Iran. As a young nature 
240 lover, Hadi joined the rangers of the Department of Environment in Kerman province for two 241 years and served partly in Khabr National Park where is close to the type locality of Persiophis 242 fahimii. He was a PhD student in IAU, Tehran, studying on the conservation of black bears in 243 southeastern Iran, but sadly passed away in an aircraft crash in Dena Mountain in central Zagros 244 in February 2018. We suggest the common name "Fahimi's Ground Snake" in English for the 245 new species.

Diagnosis. For the genus and species, Persiophis fahimii is distinguished within the subfamily Colubrinae by a combination of distinct osteological characters, including the occurrence of vestigial teeth on the palatine; a thin, edentulous pterygoid; short and blunt teeth on the maxillae and dentary, occurrence of edentulous parts on the anterior and middle region of the maxillae; a fully fused basioccipital and basisphenoid; the occurrence of a highly oblique quadrate bone attached to the posterior tip of a somewhat elongated supratemporal. The genus and species are also distinguished within the subfamily Colubrinae by a combination of morphological characters, including an elongated snout; occurrence of a rostral scale that is visible from above and wedged between the internasals; a relatively trihedral first supralabial that is slightly bigger that the second and elongated toward the tip of rostral; 15 longitudinal rows of dorsal scales on midbody; and an edentulous pterygoid.

Comparisons. The above mentioned anatomical traits are in contrast to those observed in the genus Rhynchocalamus, including a small, thin, down and backward directed premaxilla; a broad, edentulous pterygoid; relatively elongated, posteriorly curved teeth on the maxillae and dentary; a closed suture between basioccipital and basisphenoid; a short and nearly vertical quadrate bone on each side of cranium, and a broad attachment surface for a short supratemporal (Avcl et al., 2015). Also, Persiophis fahimii differs from Rhynchocalamus and Lytorhynchus in 
264 vestigial teeth except for the last two, in contrast to relatively elongated, posteriorly curved teeth 265 over most of the maxillar length in Rhynchocalamus and Lytorhynchus (Avcr et al., 2015; Leviton $266 \&$ Anderson, 1970). Persiophis differs from Dasypeltis in having smooth edges on the anterior 267 frontal and posterior nasals (compared to small premaxilla and a serrated anterior free edge of 268 frontals and posterior edges of nasals (Gans, 1952).

Description of the holotype. Body and tail slender and elongate. Head small, oblong-

270

271

272

273

274

275

276

277

278

279

280

281

282

283

284

285

286

287

Head scalation. Tip of rostral scale visible from above and wedged between the internasals. Internasal slightly shorter in length than the prefrontal scale. Width of the frontal scale is smaller than its length, shorter than parietals. Supraoculars are smaller in length and width than the frontals. Parietals elongated, medial suture between scales crooked-shaped giving an asymmetrical appearance. Nasal scale elongated and rectangular, the nostril situated upward, approximately mid length of the nasal. Loreal is small, longer than wide. $8 / 8$ (hereafter values given in right/left order) supralabials, the first supralabial is relatively trihedral, slightly bigger that the second scale and elongated toward the tip of rostral, the fourth and fifth bordering the eye. A single presubocular on each side of the head, $1 / 2$ postoculars; $3 / 2$ anterior and $3 / 3$ posterior temporals. $8 / 8$ infralabials bordering the mouth on each side of the head, the first through fifth bordering the anterior genials. On the underside of the head, the mental small and triangular. Anterior genials small, in contact with each other, obliquely elongated towards the border of mouth, median suture between the anterior genials about the length of mental scale. Posterior genials contacting each other, elongated and larger than the anterior genials, median 
288

289

290

291

292

293

294

295

296

297

298

299

300

301

302

303

304

305

306

307

308

309

310

311

suture between them slightly more than twice the length of suture between the anterior genials.

Body scalation. Dorsal scales smooth, having a single apical pit. Dorsal scales at the anterior body, midbody and posterior body are in 19, 15, and 15 longitudinal rows, respectively. Dorsal scale reduction happens at the level of 22 (DSR 19 to 18), 25 (DSR 18 to 17), 34 (DSR 17 to 16 ) and 38 (DSR 16 to 15 ) ventral scales. On the underside of the body, two preventral scales, followed by 206 ventral scales. The anal plate divided, followed by 83 pairs of subcaudal scales, ending to a single terminal scale.

Coloration. The dorsal head ground color grayish-white, with a blackish blotch on the posterior prefrontals and anterior frontal, and a parenthesis-shaped blackish blotch on the parietals. Dorsal head scale sutures with irregular feebly blackish dots. On the sides of head, irregular blackish blotches scattered around eye, a blackish stripe running from posterior eye edge along the margin of the parietal on each side of the head. Snout and labial region whitish with irregular blackish dots adjacent to the eye. The underside of the head whitish. Dorsal body and tail ground color grayish white. Three blackish longitudinal stripes on the dorsal and lateral sides of the nape, changing to continuous black blotches on dorsal surfaces of body and tail. Dorsum with nearly parallel blackish dorsal bands, having irregular margins, the width of each band about one and a half of dorsal scale length, separated by a grayish-white interspace of about the length of one scale. Body sides with continuous blackish blotches alternating with dorsal bands. Dorsal blotches fade to scattered blackish spots posteriorly on dorsal surfaces of the tail. The ventral surface of the body whitish.

Cranial Osteology. The skull in Persiophis is long and elliptical and well ossified. At the tip of the snout, the single, pyramid-shaped premaxilla is deeply wedged in the space between the septomaxillae and the nasals. The nasals are directed downward. Left and right articulated nasals form a median septum between the nasal cavities and cover it dorsally. Ventrally the 
312 nasals form a process which lies in between the two frontals. Left and right septomaxillae are 313 plate-like, bifurcate anteriorly and in contact medially. They form the floor of nasal cavity.

314 Septomaxillae contact the nasal septum medially and posteriorly form a process that contact the

315 frontals. The septomaxillae are partly fused with the vomers. The toothless vomers lie beneath

316 the two septomaxillae and form a pair of spherical cavities in which lies the vomeronasal organs.

317 The vomeronasal organs open by paired orifices into the buccal cavity. On each side of the head,

318 a cone-shaped prefrontal borders the orbit anteriorly. Dorsally, the prefrontals have a tight 319 articulation with the anterolateral surface of the frontals, and ventrally they bear a rather loose 320 articulation with the maxillae.

The neurocranium is composed of compactly ossified bones, fully fused to each other by to form a complete enclosure of the brain. Left and right frontals are well separated at the tip but joined together along the rest of their length. Parietals are ovally shaped, fused together to form a

324 single bone (largest cranial element) that dorsally roofs the braincase, bearing no elaborated crests. Laterally it extends far down either side of the brain, reaching the basisphenoid and the prootics. Left and right postorbitals articulate with the anterolateral surfaces of the parietal and form the dorsoposterior boundary of each orbit.

Left and right prootics are quadrate shaped bones, partly fused with the parietal and forming the anterior walls of each internal otic capsule. They also constitute the anterior half of each fenestra ovalis and the posterolateral wall of the braincase. Left and right supraoccipitals are fused together to form a single bone. Externally it roofs the posterior brain cavity, internally it expands to form the posterior part of each otic capsule. A pair of diagonal crests extend transversally along the posterior part of the supraoccipitals. Left and right exoccipital bones form the posterolateral wall of the braincase, as well as part of its roof. They are fused with the opisthotics and together surround the jugular foramen and extend forward to form the posterior 
336 border of the fenestra ovalis. They form the entire oval foramen magnum, except for a small

337 ventral portion of the occipital condyle. The basioccipital forms the floor of the posterior part of

338 the brain cavity and the ventral portion of the occipital condyle. It completes the foramen

339 magnum and creates a big, thick and raised occipital condyle. The basioccipital forms the

340 posterior braincase floor. The basisphenoid and parasphenoid are fused to each other to form a

341 single, long bone. It forms the posterior snout and anterior braincase floor.

342 In the palatomaxillary arches, the palatines are long and narrow, articulate with the

343 prefrontal process of the maxilla laterally and with the pterygoid posteriorly. There are three

344 small sized teeth at the mid-length of each palatine. The pterygoids are edentulous, long and bent

345 bars that are narrow anteriorly, flattened posteriorly, and extend from the posterior palatines to

346 the posterior mandibles. The ectopterygoids are flat, bifurcate anteriorly, notched posteriorly and

347 connect the maxillae to the pterygoids. Left and right maxillae are curved, anteriorly thin,

348 posteriorly somewhat broadened and connect to the flattened ventral surface of the ectopterygoid

349 by a mesial process. The maxilla medially articulates with the ventral surface of the prefrontal.

350 Each maxilla is edentulous anteriorly, bears three small teeth, and after another edentulous

351 medial region, bears $6 / 5$ small teeth. Finally, after a small space (equal to the length of one

352 socket) two big, elongated, posteriorly curved teeth are present. In the medial, edentulous region

353 of the left maxilla, a small socket is observed.

354 The mandibular units are composed of compactly ossified bone elements. Left and right

355 supratemporals are narrow, flattened, dermal elements, connected to the proximal end of 356 quadrates and the posterolateral part of braincase by fibrous connective tissue. Each 357 supratemporal is long, slightly bent upward, and overlays the exoccipital, prootic and even 358 reaches the edge of the parietal. Left and right quadrates are long, tick, rectangular shaped, 359 having a flattened proximal end aligned along the posterolateral border of each supratemporal. 
360 The distal articulating surface of each quadrate is extended transversely and directed backward.

361 Left and right mandibles are long, dorsally concave, connected to each other anteriorly by an

362 elastic ligament. Each mandible unit is composed of two major bones, a compound bone and 363 dentary. The dentary is somewhat dorsally curved and bears sockets for closely set 18/19 (L/R) 364 small teeth that decrease in size posteriorly. Left and right stapes (columella) are slender, rod like 365 bones, proximally enlarged and form a footplate that fit into the fenestra ovalis, distally connect 366 to the inner surface of the quadrate at about mid length level.

Natural history. Our data on biology of Persiophis fahimii is based on the one specimen

368

369

370

371

372

collected. The holotype was collected at elevation of 1350 meters ASL on a bare mountainside, while climbing on a vertical rocky wall, at late night (2.30 AM). The mountain is composed of Devonian limestone marbles, at the southeastern edge of the central mountains of Iran, ranging from 1050 to 1600 meters ASL. Dominant vegetation on the plain in front of the mountain is Calligonum and annual forbs and grasses. At the base of the mountain, the vegetation changes to Calligonum and Ziziphus nummularia. At the type locality, the vegetation is dominated by sparse woody, thorny or aromatic shrubs, including Periploca sp. (Apocynaceae), Dichanthium sp. (Poaceae), Fagonia sp. (Zygophyllaceae), Ephedra foliata (Ephedraceae), Teucrium sp. (Lamiaceae), Lophochloa sp. (Poaceae), Lycium sp. (Solanaceae), Tribulus sp. (Zygophyllaceae), Pulicaria sp. (Asteraceae), Reseda sp. (Resedaceae), Heliotropium sp. (Boraginaceae), Gymnocarpos decander (Caryophyllaceae), Convolvulus sp. (Convolvulaceae), Heliantemum sp. (Cistaceae), and Diceratella persica (Apiaceae).

Conservation. Since the first field expedition in 2008 and two more field expeditions in spring 2017 and 2018 in the type locality of Persiophis fahimii failed to find any additional specimens of this snake, we assume that this snake is a very rare species with a limited local distribution. Currently, there is not enough data to evaluate the conservation status of Persiophis 
384 fahimii; hence, further expeditions are needed to shed light on the distribution and ecology of this 385 snake. We suggest it be considered to have the IUCN Red List status 'DD - Data Deficient.' But

386

researchers should take care in studying the species, avoiding over collecting or disturbing the habitat. We suggest that the local conservation management around the type locality of the species is urgently required.

\section{DISCUSSION}

\section{Additional information on Dolichophis andreanus (Werner, 1917) comb. nov.}

Though Hierophis andreanus was originally described as Zamenis andreana by Werner (1917), it was an unknown and forgotten snake not listed in regional checklists (Latifi, 1991; Leviton et al., 1992) until researchers in the first decade of 21st century shed light on its distribution (Rajabizadeh \& Rastegar-Pouyani, 2006; Rajabizadeh \& Rastegar-Pouyani, 2009; Schätti, 2001). Since the genetic proximity of the species to dwarf snakes (genus Eirenis) and morphologic similarity to whip snakes (genera Hierophis and Dolichophis) were in contrast (Schätti \& Monsch, 2004), its taxonomy was obscure and authors referred to it as Coluber (s. 1.) andreanus (Rajabizadeh \& Rastegar-Pouyani, 2006). Rastegar-Pouyani et al. (2008) erroneously listed this species in the genus Zamenis. Torki (2010) assigned the species to the genus Hierophis without any taxonomic justification. Surprisingly, other authors followed this classification without further questioning its taxonomic status (Chefaoui et al., 2018; Wallach et al., 2014). Recent phylogenetic studies on snakes cast doubt on the taxonomic placement of Hierophis andreanus within the genus Hierophis (Figueroa et al., 2016). Our molecular phylogenetic results clearly indicate placement of Hierophis andreanus within the genus Dolichophis (Fig. 2), hence we suggest the new combination Dolichophis andreanus (Werner, 
1917) comb. nov.

From a comparative point of view, the overall shape of skull and neurocranium in Dolichophis andreanus generally resembles that of Eirenis more than Hierophis and Dolichophis (Fig. 6). In both D. andreanus and Eirenis, the neurocranium is wide, ovally shaped, bearing no elaborated V-shaped pair of crests on the parietal bones, and the braincase is large. The skull is long and elliptical, well ossified and composed of relatively thick bones. On the tip of the snout, there is a single, pyramid-shaped bone (premaxilla), that is dorsally wedged between the nasals, and like Eirenis, it is projected less anteriorly than in Hierophis and Dolichophis. Compared to whip snakes, the neurocranium in Dolichophis andreanus is wider, bearing a less-elaborated Vshaped pair of crests on the parietal bones, again resembling Eirenis. The CT-scanned Dolichophis andreanus specimen has 10/10, 9/9, 10/9, 15/13 curved teeth on maxilla, palatine, pterygoid and dentary bone.

Based on the head and body scalation data, Schätti \& Monsch (2004) inferred a sistergroup relationship between Dolichophis andreanus and dwarf snakes of the genus Eirenis, especially based on similar traits including the low number of supralabial, infralabial, anterior temporal and dorsal scale rows. Morphological similarity between Dolichophis andreanus and Eirenis is striking. The evolutionary history of head and dorsal body scales, as well as total size shows that the most parsimonious state for the common ancestor of Western Palearctic racers, whip snakes and dwarf snakes is a large-size snake (total size more than one meter) having two anterior temporals, 8 supralabials, 9-10 infralabials and 19 dorsal scales. Total size of less than one meter, a single anterior temporal as well as 15, 17 and 18 dorsal body scales evolved independently in both Eirenis and D. andreanus. The number of supralabials and infralabials is not totally unique in dwarf snakes, hence 7-8 supralabials and 7-9 infralabials are present in the genus Eirenis and in D. andreanus as well. 
433

434

435

436

437

438

439

440

441

442

443

444

445

446

447

\section{Additional information on Muhtarophis barani (Olgun et al., 2007)}

Although previous phylogenetic studies did not unambiguously resolve the phylogenetic position of Muhtarophis barani or Baran's Black-headed Dwarf Snake (Avcr et al., 2015; Šmíd et al., 2015; Tamar et al., 2016), our tree surprisingly places it strongly as the sister group to the genus Scaphiophis. African Shovel-nosed Snakes (S. albopunctatus Peters, 1870 and S. raffreyi Bocourt, 1875) are large-sized snakes, maximum total length around 150 centimeters (Broadley, 1994), distributed around the periphery of the Central African rain forest from Ghana to western Ethiopia and adjacent Sudan (Largen \& Rasmussen, 1993). In contrast, Muhtarophis is a dwarfed ground snake with maximum total length around 40 centimeters, reported from Hatay Province, Southern Turkey (Avcr et al., 2015).

The skull in Scaphiophis is robust, the premaxilla is large, beak shaped and divides the nasals, and each lateral projection of premaxilla is actually indeed divided into two lobes, the posterior nasals are articulated to the middle of the anterior frontal, the quadrate is not oblique nor slanting backward, dentition in a sample of $S$. albopunctatus is maxillary 15, palatine 9, pterygoid 8, dentary 18, and in a sample of $S$. raffreyi is 13, 7, 7, 16 respectively (Bourgeois, 1968; Broadley, 1994). In Muhtarophis, the skull is also robust, having a large pyramid shaped premaxilla that is wedged between the anterior nasals. The posterior nasal is broadly articulated to the anterior frontal, the quadrate is more or less vertical, and the dentition in two examined samples consists of six maxillary 6 heterogeneous teeth ( 5 same size anterior teeth and one about two times larger rear tooth), palatine 4, pterygoid 8, dentary 9 (Avcr et al., 2015). Though there are some shared osteological traits between Scaphiophis and Muhtarophis, the obvious differences in osteology of these genera makes a sister group relationship doubtful, despite the strong support estimated here. The variable placement among the phylogenetic analyses may 
456 result from a lack of taxon sampling, or more likely, inadequate sampling of independent loci

457 and phylogenetically informative molecular characters. Hence, further research is needed to 458 identify the phylogenetic position of Muhtarophis.

459

460

461

462

463

464

465

466

467

468

469

470

471

472

473

474

475

476

477

478

479

3

4

6

\section{The challenge of monotypy}

Since currently only one species is known in Persiophis, the genus is monotypic. Moreover, the sole species is known only from a single specimen, which is a common problem in squamate taxonomy (Meiri et al., 2018). Two scenarios exist which may, in the future, avoid the challenge of monotypy and demonstrate monophyly of the genus based on cladistic theory, which generally demands that a genus is a monophyletic group of species; thus, monotypic genera are not phylogenetically informative (Platnick, 1976). First, since the reptile fauna (especially snakes) of southwestern Asia is not sufficiently studied and many undescribed taxa still likely remain (Rajabizadeh, 2018), it is possible that other species within the genus Persiophis exist that have not been discovered to date, either extant or in the fossil record. Regardless, since the species Persiophis fahimii is strongly supported as a lineage distinct from any existing snake genera, based on the molecular phylogeny and osteological analyses, we here accept it as a representative of a distinct genus Persiophis that is currently monotypic.

\section{CONCLUSIONS}

Here, we present new molecular sequence data and a new phylogenetic analysis of snakes, focusing primarily on Colubrinae from southwestern Asia. We find continued uncertainty in the placement of the enigmatic Turkish genus Muhtarophis based on osteological comparisons, 
480 despite strong support in the phylogenetic analysis. On the basis of the tree and morphology, we

481

482 483 484 485 486 487 488 490 confidently reassign Hierophis andreanus from Hierophis to Dolichophis, hereafter referred to Dolichophis andreanus. Our morphological and molecular data also suggest a potential instance of convergent miniaturization in these Old-World racers. Finally, we report on the discovery of a new genus and species of ground snake, Persiophis fahimii, from southeastern Iran. Our data highlight the importance of broad phylogenetic sampling and ground-level field research to gather an accurate picture of global biodiversity, phylogenetic relationships, and evolutionary patterns in groups such as snakes.

\section{ACKNOWLEDGMENTS}

We are grateful to Eskandar Rastegar-Pouyani for his kind assistance in the field and reviewing the manuscript. Thanks to Firouzeh Bordbar (Bahonar University, Kerman) for identification of plant species. We are also grateful to Jens Vindum and Lauren Scheinberg (CAS) and Ted Papenfuss (MVZ) for their assistance. Also we thank Daniel Melnikov, Hossein Nabizadeh and Morteza Moaddab for their help in the field. We thank Justin L. Lee (NMNH) and an anonymous reviewer for their useful suggestions which helped us to improve the previous version of our manuscript. 


\section{REFERENCES}

Anisimova M, Gil M, Dufayard J-F, Dessimoz C, Gascuel O. 2011. Survey of branch support methods demonstrates accuracy, power, and robustness of fast likelihood-based approximation schemes. Systematic Biology 60:685-699.

Avcı A, Ilgaz Ç, Rajabizadeh M, Yılmaz C, Üzüm N, Adriaens D, Kumlutaş Y, and Olgun K. 2015. Molecular phylogeny and micro-CT scanning revealed extreme cryptic biodiversity in Kukri snake, Muhtarophis gen. nov., a new genus for Rhynchocalamus barani (Serpentes: Colubridae). Russian Journal of Herpetology 22:159-174.

Bocourt F. 1875. Note sur une nouvelle espece d'Ophidien. Annales des Sciences Naturelles (Zoologie), Paris Ser. 6 2:3.

Böhm M, Collen B, Baillie JE, Bowles P, Chanson J, Cox N, Hammerson G, Hoffmann M, Livingstone SR, Ram M. 2013. The conservation status of the world's reptiles. Biological Conservation 157:372-385. https://doi.org/10.1016/j.biocon.2012.07.015

Boulenger G. 1898. XIX.- On a second collection of reptiles made by Mr. E. Lort-Phillips in Somaliland. Journal of Natural History 2:130-133.

Bourgeois M. 1968. Contribution a 1 a morphologie comparee $\mathrm{d}$ u crane des ophidiens de I' Afrique centrale. Publications de I'Universite Officielle du Congo a Lubumbashi, Lubumbashi 18:1-293.

Broadley D. 1994. A revision of the African genus Scaphiophis Peters (Serpentes: Colubridae). Herpetological Journal 4:1-10.

Broeckhoven C, du Plessis A. 2017. Has snake fang evolution lost its bite? New insights from a structural mechanics viewpoint. Biology Letters 13:20170293.

Chan-Ard T, Nabhitabhata J, Parr JW. 2015. A field guide to the reptiles of Thailand: Oxford University Press, New York.

Chefaoui RM, Hosseinzadeh MS, Mashayekhi M, Safaei-Mahroo B, Kazemi SM. 2018. Identifying suitable habitats and current conservation status of a rare and elusive reptile in Iran. Amphibia-Reptilia 39:355-362. https://doi.org/10.1163/15685381-17000185

Chernomor O, von Haeseler A, Minh BQ. 2016. Terrace aware data structure for phylogenomic inference from supermatrices. Systematic Biology 65:997-1008.

Chippaux J-P, Jackson K. 2019. Snakes of central and western Africa, Johns Hopkins University Press, Baltimore.

Das S, Campbell P, Roy S, Mukherjee S, Pramanick K, Biswas A, Raha S. 2019. Cranial osteology and molecular phylogeny of Argyrogena fasciolata (Shaw, 1802) (Colubridae: Serpentes). Vertebrate Zoology 69(3):311-325.

Figueroa A, McKelvy AD, Grismer LL, Bell CD, Lailvaux SP. 2016. A species-level 
phylogeny of extant snakes with description of a new colubrid subfamily and genus. PLoS One 11:e0161070. https://doi.org/10.1371/journal.pone.0161070

Gans C. 1952. The functional morphology of the egg-eating adaptations in the snake genus Dasypeltis. Zoologica 37:209-244.

Gans C. 1954. Present knowledge of the snake Elachistodon westermanni. Reinhardt Breviora 36:1-17.

Hoang DT, Chernomor O, Von Haeseler A, Minh BQ, Vinh LS. 2017. UFBoot2: improving the ultrafast bootstrap approximation. Molecular Biology and Evolution 35:518-522.

Hosseinian Yousefkhani SS, Rajabizadeh M. 2014. Skull comparison between Eirenis collaris and Dolichophis jugularis (Serpentes: Colubridae) from Iran. Iranian Journal of Animal Biosystematics 10:87-100. https://doi.org/10.22067/ijab.v10i2.34202

Kalyaanamoorthy S, Minh BQ, Wong TK, von Haeseler A, Jermiin LS. 2017. ModelFinder: fast model selection for accurate phylogenetic estimates. Nature methods 14:587.

Kardong KV. 1979. 'Protovipers' and the Evolution of Snake Fangs. Evolution 33:433-443. $10.2307 / 2407632$

Kharin B, Akulenko M. 2008. Rare and little-known snakes of North-Eastern Eurasia. 1. A new record of Hierophis spinalis (Colubridae) from Russian Far East. Sovremennaya Gerpetologiya (Modern Herpetology) 8:160-169.

Largen MJ, Rasmussen JB. 1993. Catalogue of the snakes of Ethiopia (Reptilia Serpentes), including identification keys. Tropical Zoology 6:313-434.

Latifi M. 1991. The snakes of Iran: Society for the Study of Amphibians and Reptiles, Ithaca.

Lawson R, Slowinski JB, Crother BI, Burbrink FT. 2005. Phylogeny of the Colubroidea (Serpentes): new evidence from mitochondrial and nuclear genes. Molecular Phylogenetics and Evolution 37:581-601. https://doi.org/10.1016/j.ympev.2005.07.016

Leviton AE, Anderson SC. 1970. Review of the snakes of the genus Lytorhynchus. Proceedings of the California Academy of Sciences (Ser 4) 37:249-274.

Leviton AE, Anderson SC, Adler K, Minton SA. 1992. Handbook to Middle East amphibians and reptiles: Society for the Study of Amphibians and Reptiles, St. Louis.

Mahlow K, Tillack F, Schmidtler JF, Müller J. 2013. An annotated checklist, description and key to the dwarf snakes of the genus Eirenis Jan, 1863 (Reptilia: Squamata: Colubridae), with special emphasis on the dentition. Vertebrate Zoology 63:41-85.

Marx H. 1959. Review of the colubrid snake genus Spalerosophis. Fieldiana Zoology 39:347361.

Meiri S, Bauer AM, Allison A, Castro - Herrera F, Chirio L, Colli G, Das I, Doan TM, Glaw F, Grismer LL, Hoogmoed M, Kraus F, LeBreton M, Meirte D, Nagy ZT, Nogueira CC, Oliver P, Pauwels OSG, Pincheira-Donoso D, Shea G SR, Tallowin 
OJS, Torres-Carvajal O, Trape JF UP, Wagner P, Wang Y, Ziegler T, Roll U. 2018. Extinct, obscure or imaginary: The lizard species with the smallest ranges. Diversity and Distributions 24:262-273. https://doi.org/10.1111/ddi.12678

Mirza ZA, Patel H. 2018. Back from the dead! Resurrection and revalidation of the Indian endemic snake genus Wallophis Werner, 1929 (Squamata: Colubridae) insights from molecular data. Mitochondrial DNA Part A 29:331-334. https://doi.org/10.1080/24701394.2016.1278536

Mirza ZA, Vyas R, Patel H, Maheta J, Sanap RV. 2016. A new miocene-divergent lineage of old world racer snake from India. PLoS One 11:e0148380. https://doi.org/10.1371/journal.pone.0148380

Nagy Z, Lawson R, Joger U, Wink M. 2004. Molecular systematics of racers, whipsnakes and relatives (Reptilia: Colubridae) using mitochondrial and nuclear markers. Journal of Zoological Systematics and Evolutionary Research 42:223-233. https://doi.org/10.1111/j.1439-0469.2004.00249.x

Nguyen L-T, Schmidt HA, von Haeseler A, Minh BQ. 2014. IQ-TREE: a fast and effective stochastic algorithm for estimating maximum-likelihood phylogenies. Molecular biology and evolution 32:268-274.

Nguyen HN, Tran BV, Nguyen LH, Neang T, Yushchenko PV, Poyarkov NA. 2020. A new species of Oligodon Fitzinger, 1826 from Langbian Plateau, southern Vietnam, with additional information on Oligodon annamensis Leviton, 1953 (Squamata: Colubridae). PeerJ 8:e8332. http://doi.org/10.7717/peerj.8332

Olgun K, Avci A, Ilgaz C, Uezuem N, Yilmaz C. 2007. A new species of Rhynchocalamus (Reptilia: Serpentes: Colubridae) from Turkey. Zootaxa 1399:57-68. https://doi.org/10.11646/zootaxa.1399.2

Padial JM, Miralles A, De la Riva I, Vences M. 2010. The integrative future of taxonomy. Frontiers in Zoology 7:16. https://doi.org/10.1186/1742-9994-7-16

Peters W. 1870. Eine Mitteilung über neue Amphibien (Hemidactylus, Urosaurus, Tropidolepisma, Geophis, Uriechis, Scaphiophis, Hoplocephalus, Rana, Entomoglossus, Cystignathus, Hylodes, Arthroleptis, Phyllobates, Cophomantis) des Kö niglich zoologischen Museums. Monatsberichte der Königlich Akademie der Wissenschaften zu Berlin 1870:641-652.

Platnick NI. 1976. Are monotypic genera possible? Systematic Zoology 25:198-199.

Poyarkov NA, Nguyen TV, Vogel G. 2019. A new species of the genus Liopeltis Fitzinger, 1843 from Vietnam (Squamata: Colubridae). Journal of Natural History 53:1647-1672.

Pyron RA, Burbrink FT, Colli GR, De Oca ANM, Vitt LJ, Kuczynski CA, Wiens JJ. 2011. The phylogeny of advanced snakes (Colubroidea), with discovery of a new subfamily and 
605

606

607

608

609

610

611

612

613

614

615

616

617

618

619

620

621

622

623

624

625

626

627

628

629

630

631

632

633

634

635

636

637

638

639

640

comparison of support methods for likelihood trees. Molecular Phylogenetics and Evolution 58:329-342. https://doi.org/10.1016/j.ympev.2010.11.006

Pyron RA, Burbrink FT, Wiens JJ. 2013. A phylogeny and revised classification of Squamata, including 4161 species of lizards and snakes. BMC Evolutionary Biology 13:93. https://doi.org/10.1186/1471-2148-13-93

Rajabizadeh M, Rastegar-Pouyani N. 2006. Additional information on the distribution and morphology of Coluber (sl) andreanus (Werner, 1917) (Reptilia: Colubridae) from Iran. Zoology in the Middle East 39:69-74. https://doi.org/10.1080/09397140.2006.10638184

Rajabizadeh M, Rastegar-Pouyani N. 2009. Two new records of reptiles (Reptilia: Squamata) from southeastern Iran. Turkish Journal of Zoology 33:103-104.

Rajabizadeh M. 2018. Snakes of Iran. Tehran, Iran: Iranshenasi.

Rastegar-Pouyani N, Kami HG, Rajabzadeh H, Shafiei S, Anderson SC. 2008. Annotated checklist of amphibians and reptiles of Iran. Iranian Journal of Animal Biosystematics 4:43-66. https://doi.org/10.22067/ijab.v11i1.37543

Saleh M, Sarhan M. 2016. The egg-eating snake (Colubridae: Dasypeltis) of Faiyum, Egypt, with the description of a new species. Bulletin de la Société Herpétologique de France 160:25-48.

Schätti B. 1985. Systematics of east african species of Meizodon fischer, 1856 (Reptilia Serpentes Colubridae) Pubblicazioni del centro di studio per la faunistica ed ecologia tropicali Del CNR: CCLXXIII. Monitore Zoologico Italiano Supplemento 20:149-175.

Schätti B. 1987. The phylogenetic significance of morphological characters in the Holarctic racers of the genus Coluber Linnaeus, 1758 (Reptilia, Serpentes). Amphibia-Reptilia 8:401-415.

Schätti B. 2001. Morphologie und Verbreitung von Coluber (sensu lato) andreanus (Werner 1917) (Reptilia: Squamata: Colubridae). Revue Suisse de Zoologie 108:487-493. https://doi.org/10.5962/bhl.part.80158

Schätti B, Monsch P. 2004. Systematics and phylogenetic relationships of whip snakes (Hierophis Fitzinger) and Zamenis andreana Werner, 1917 (Reptilia: Squamata: Colubrinae). Revue Suisse de Zoologie 111:239-256. https://doi.org/10.5962/bhl.part.80237

Stamatakis A. 2014. RAxML version 8: a tool for phylogenetic analysis and post-analysis of large phylogenies. Bioinformatics 30:1312-1313.

Torki F. 2010. Die Andreas-Zornnatter Hierophis andreanus (Werner, 1917) im Westen des Iran. Sauria 32:27-32.

Tsai T-S, Mao J-J. 2017. Species identification of shed snake skins in Taiwan and adjacent islands. Zoological Studies 56:1-23. 
641

642

643

644

645

646

647

Uetz P, Freed P, Hosek J. 2020. The reptile database. Available at http:// reptile-database. reptarium.cz/ (accessed on 25 February 2020).

Utiger U, Schätti B, Helfenberger N. 2005. The Oriental colubrine genus Coelognathus Fitzinger, 1843, and classification of Old and New World racers and ratsnakes (Reptilia, Squamata, Colubridae, Colubrinae). Russian Journal of Herpetology 12:39-60.

Vidal N, Delmas A-S, David P, Cruaud C, Couloux A, Hedges SB. 2007. The phylogeny and classification of caenophidian snakes inferred from seven nuclear protein-coding genes. Comptes Rendus Biologies 330:182-187. https://doi.org/10.1016/j.crvi.2006.10.001

Vitt LJ, Caldwell JP. 2013. Herpetology: an introductory biology of amphibians and reptiles: Academic press.

Vlassenbroeck J, Dierick M, Masschaele B, Cnudde V, Van Hoorebeke L, Jacobs P. 2007. Software tools for quantification of X-ray microtomography at the UGCT. Nuclear Instruments and Methods in Physics Research Section A: Accelerators, Spectrometers, Detectors and Associated Equipment https://doi.org/10.1016/j.nima.2007.05.073

Wade EO. 2008. New reconstructive methods in scientific illustration with reference to systematic herpetology. PhD thesis. Middlesex University.

Wagner P, Böhme W. 2007. Herpetofauna Kakamegensis-the amphibians and reptiles of Kakamega Forest, western Kenya. Bonner Zoologische Beiträge 55:123-150.

Wallach V, Lanza B, Nistri A. 2010. Aprosdoketophis andreonei, a new genus and species of snake from Somalia (Serpentes: Colubridae: Boiginae). African Journal of Herpetology 59:95-110.

Wallach V, Williams KL, and Boundy J. 2014. Snakes of the world: a catalogue of living and extinct species: CRC Press.

Wang P, Shi L, Guo P. 2019. Morphology-based intraspecific taxonomy of Oreocryptophis porphyraceus (Cantor, 1839) in mainland China (Serpentes: Colubridae). Zoological Research 40:324-330.

Werner F. 1917. Reptilien aus Persien (Provinz Fars). Verhandlungen der kaiserlichköniglichen zoologisch-botanischen Gesellschaft in Wien 67:191-220.

Zaher H, Murphy RW, Arredondo JC, Graboski R, Machado-Filho PR, Mahlow K, Montingelli GG, Quadros AB, Orlov NL, Wilkinson M. 2019. Large-scale molecular phylogeny, morphology, divergence-time estimation, and the fossil record of advanced caenophidian snakes (Squamata: Serpentes). PLoS One 14:e0216148.

Zaher HED, Grazziotin FG, Graboski R, Fuentes RG, Sánchez-Martinez P, Montingelli GG, Zhang Y-P, Murphy RW. 2012. Phylogenetic relationships of the genus Sibynophis (Serpentes: Colubroidea). Papéis Avulsos de Zoologia 52:141-149. 
677

678

679

680

681

682

683

684 https://doi.org/10.1590/s0031-10492012001200001

Zheng Y, Wiens JJ. 2016. Combining phylogenomic and supermatrix approaches, and a timecalibrated phylogeny for squamate reptiles (lizards and snakes) based on 52 genes and 4162 species. Molecular Phylogenetics and Evolution 94:537-547. https://doi.org/10.1016/j.ympev.2015.10.009

Zwickl DJ, Hillis DM. 2002. Increased taxon sampling greatly reduces phylogenetic error. Systematic Biology 51:588-598. https://doi.org/10.1080/10635150290102339 


\section{Table 1 (on next page)}

Additional specimens added to the matrix of Figueroa et al. (2016). 


\begin{tabular}{|c|c|c|c|}
\hline Species & Locality & Voucher & Reference \\
\hline Muhtarophis barani & - & ZMHRU2014/60-5 & Tamar et al., 2016 \\
\hline Wallaceophis gujaratensis & - & NCBS HA-105 & Mirza et al., 2016 \\
\hline Wallophis brachyura & - & - & Mirza \& Patel, 2018 \\
\hline Lytorhynchus maynardi & Iran & MVZ234499 & Tamar et al., 2016 \\
\hline Lytorhynchus maynardi & Pakistan & MVZ248463 & Tamar et al., 2016 \\
\hline Lytorhynchus gaddi & Iran & MVZ234500 & Tamar et al., 2016 \\
\hline Lytorhynchus diadema & Oman & CN4093 & Tamar et al., 2016 \\
\hline Lytorhynchus diadema & Morocco & IBES1329 & Tamar et al., 2016 \\
\hline Lytorhynchus diadema & Egypt & SPM002589 & Tamar et al., 2016 \\
\hline Rhynchocalamus satunini & Iran & CAS228723 & Tamar et al., 2016 \\
\hline Rhynchocalamus satunini & Turkey & ZMHRU2015/0 & Tamar et al., 2016 \\
\hline Rhynchocalamus arabicus & Oman & CN4780 & Tamar et al., 2016 \\
\hline Rhynchocalamus dayanae & Israel & TAU.R17093 & Tamar et al., 2016 \\
\hline $\begin{array}{l}\text { Rhynchocalamus } \\
\text { melanocephalus }\end{array}$ & Israel & HUJ.R22054 & Tamar et al., 2016 \\
\hline
\end{tabular}




\section{Figure 1}

Distribution map of Persiophis fahimii Gen. et sp. nov. (star) and Hierophis andreanus (circle) in Iran.

Localities of Hierophis andreanus are based on Rajabizadeh (2018). Arrows indicate the locality of Hierophis andreanus specimens for which genetic data were included in the molecular phylogenetic analysis, along with Persiophis fahimii Gen. et sp. nov. 


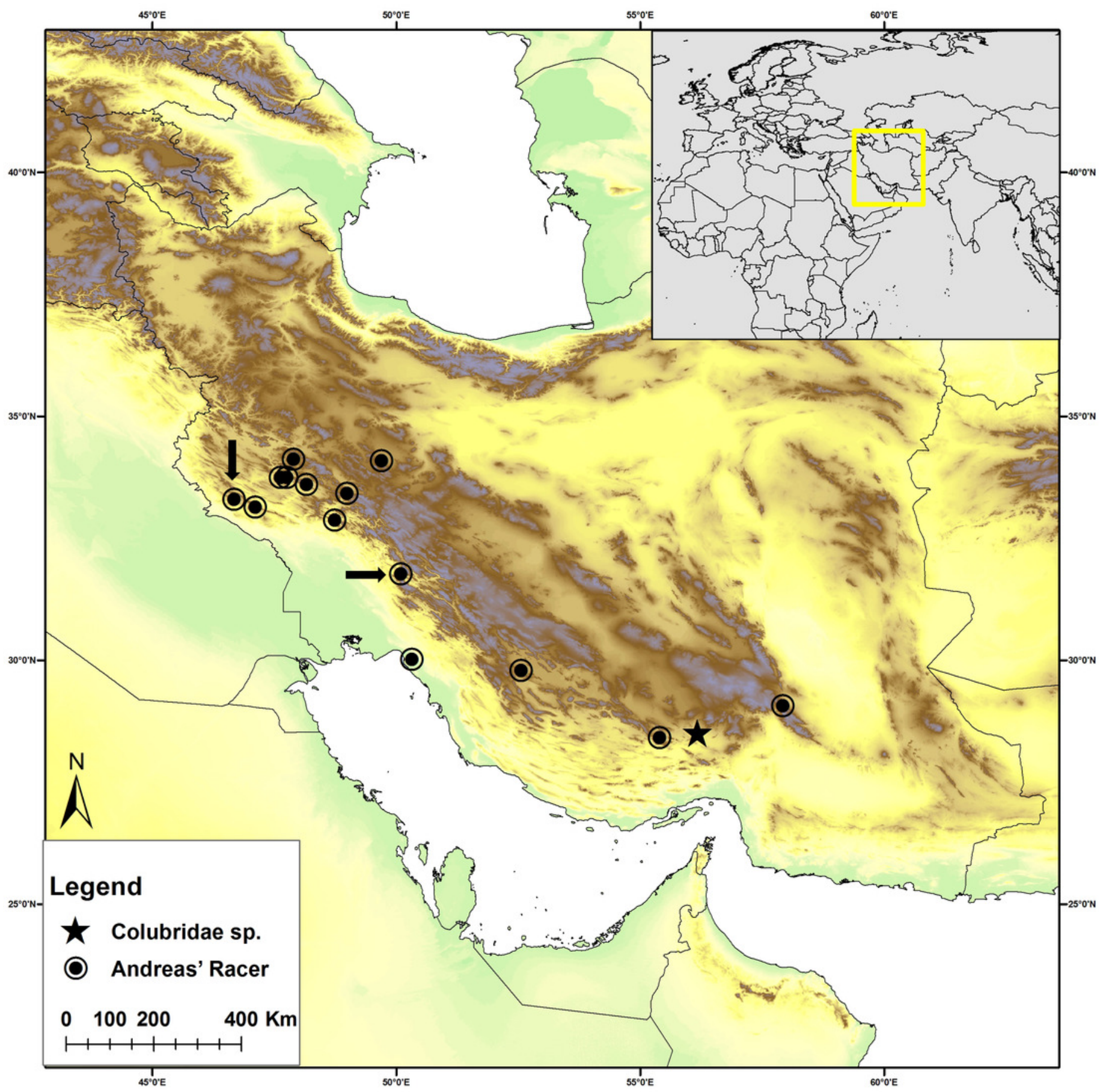




\section{Figure 2}

Phylogenetic relationships of Western Palearctic Colubrids.

(A) Resulting topology and UF/SHL-support values from reanalysis of the matrix of (Figueroa et al., 2016) with additional colubrines from SW Asia; (B) phylogenetic relationships within the clade of Western Palearctic colubrids. The species Hierophis andreanus is nested within Dolichophis with strong support, while Persiophis fahimii Gen. et sp. nov. forms a distinct lineage as the sister group to Rhynchocalamus and clearly represents a new genus and species. 


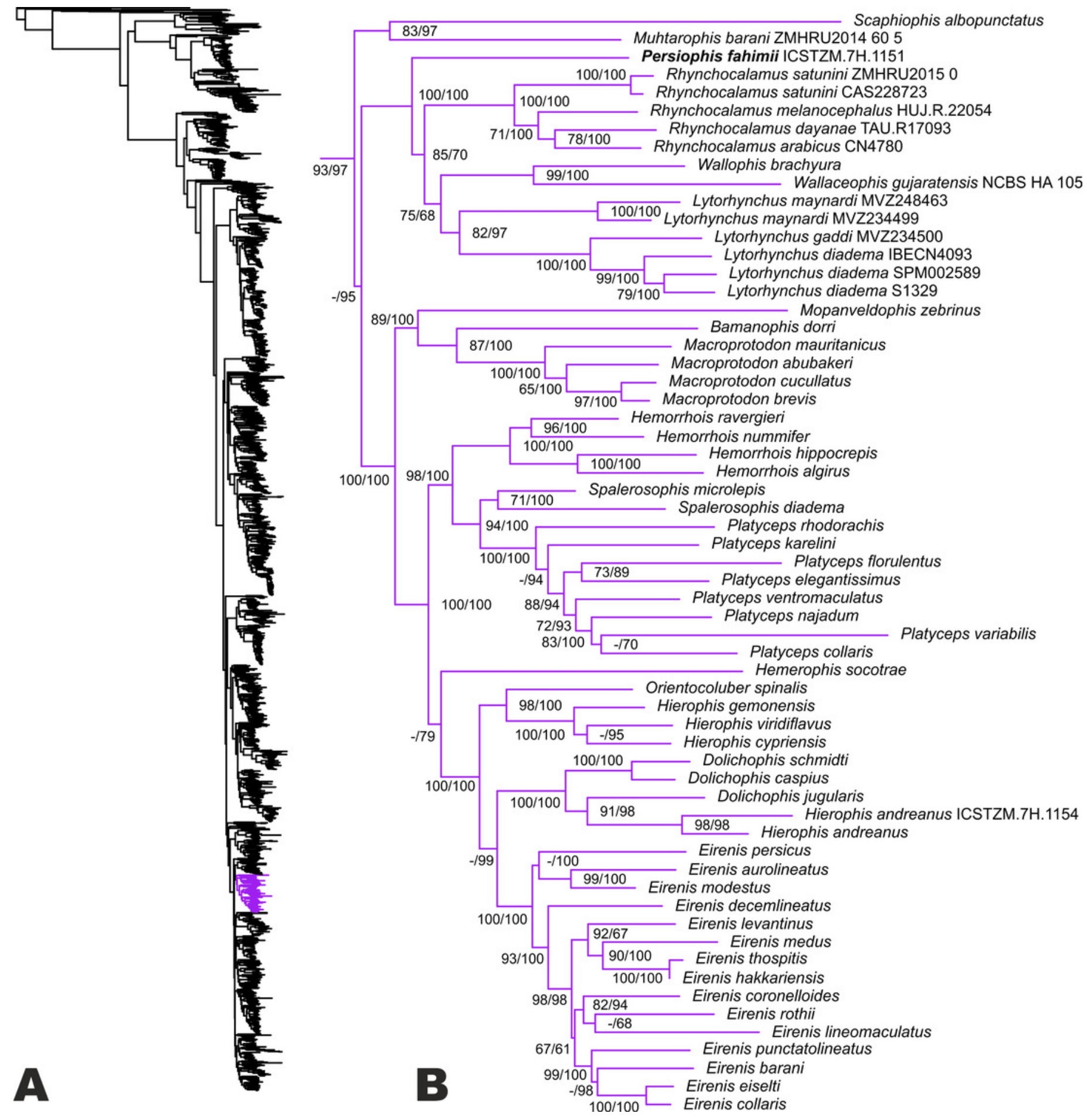


Figure 3

The holotype of Persiophis fahimii Gen. et sp. nov., live specimen in situ.

Details of head scalation in close-up (a) lateral, (b) ventral and (d) dorsal views; (s) lateral view of the fore body, and (e) dorsal view of the whole body. Photos by Roman A. Nazarov. 

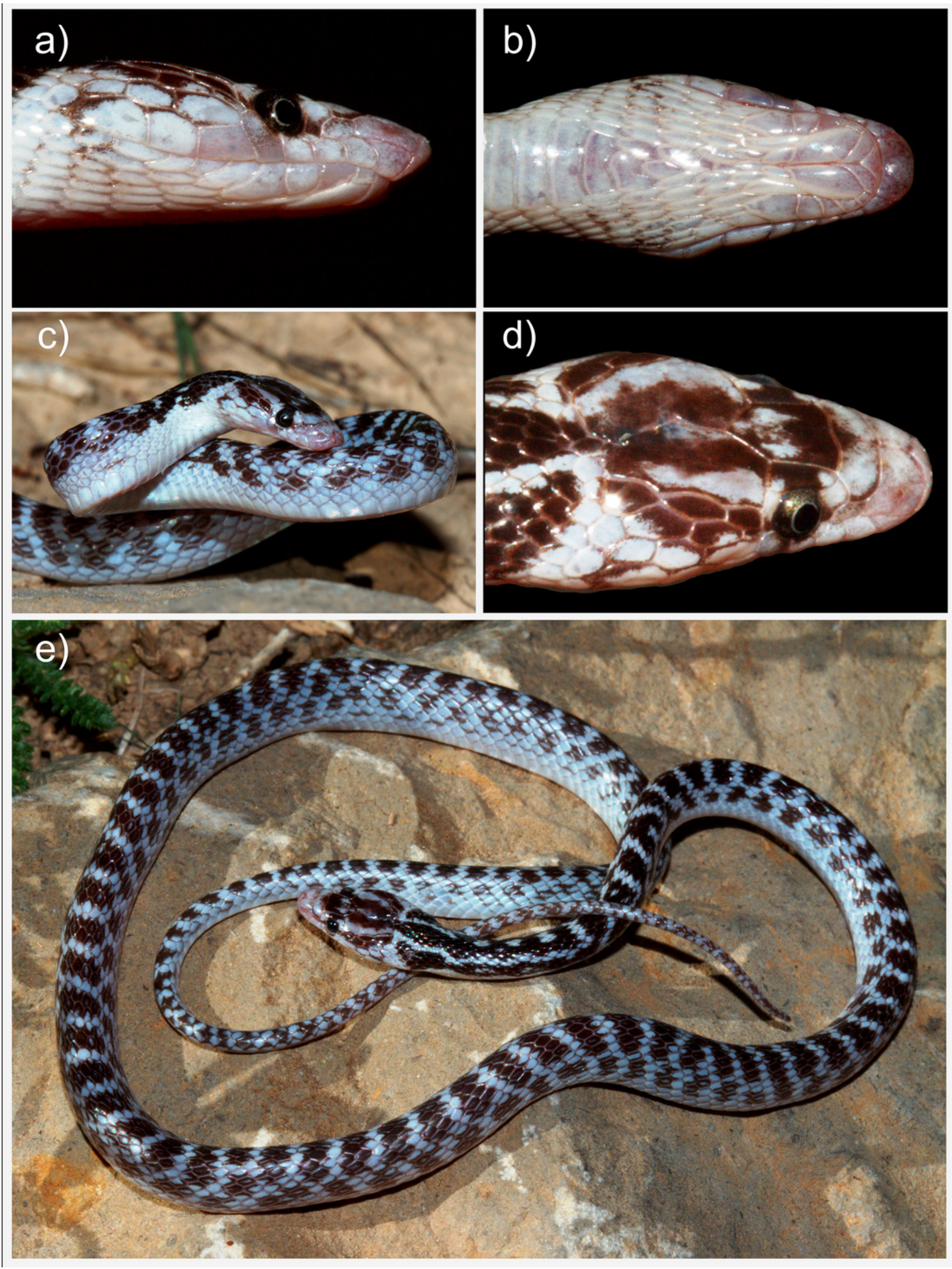
Figure 4

Micro-CT reconstruction of the skull of Persiophis fahimii Gen. et sp. nov.

(a) Lateral, (b) dorsal, (c) ventral and (d) sagittal views of the skull of the holotype.

Visualization by Mahdi Rajabizadeh. 

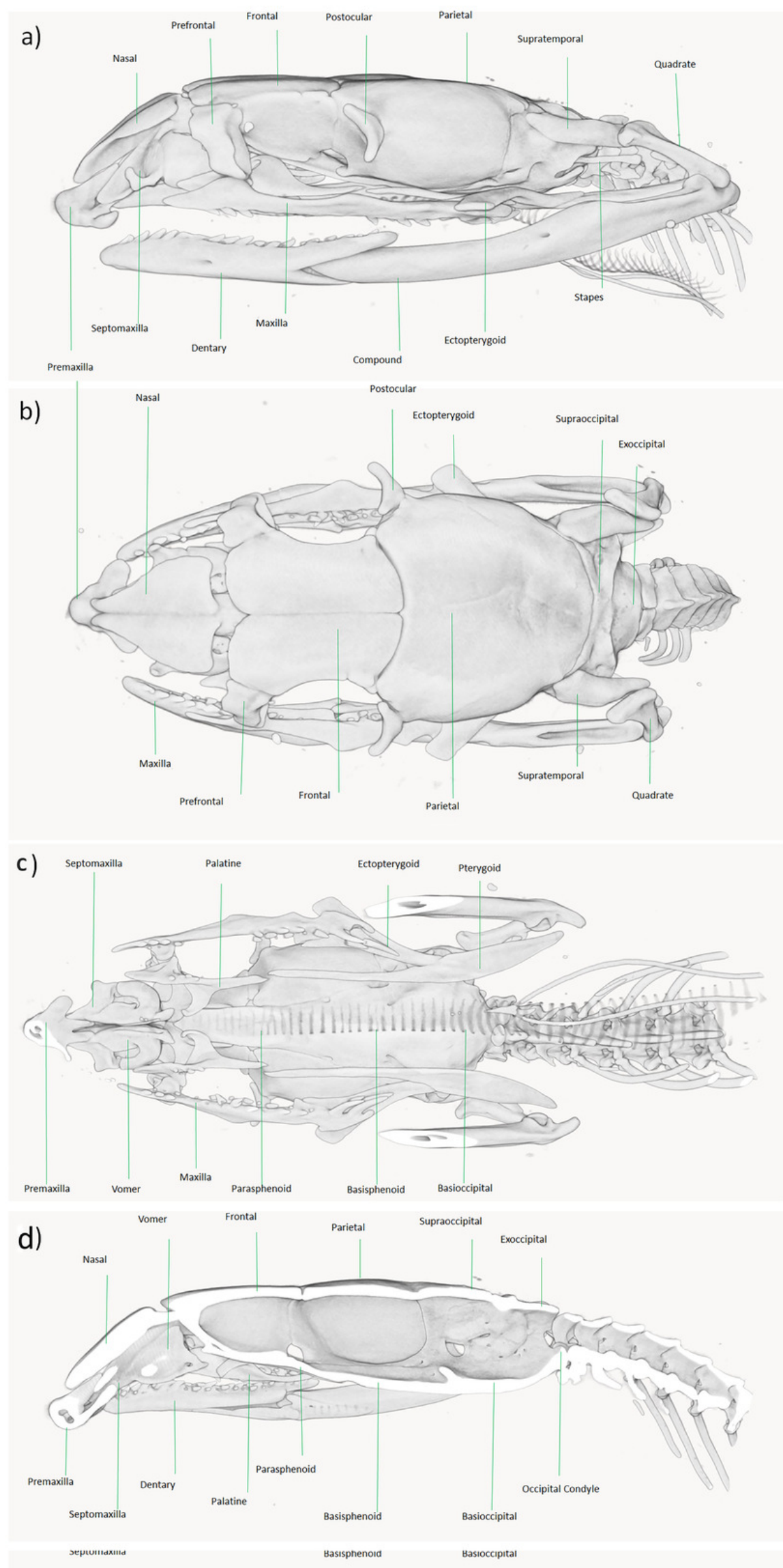
Figure 5

Habitat of Persiophis fahimii Gen. et sp. nov. at the type locality in vicinity of Orzueeyeh City, Kerman Province, Southern Iran.

(a) Macrohabitat, arrow indicates the place where the snake was collected; (b) microhabitat at the site of collection of the type specimen. Photos by Mahdi Rajabizadeh. 


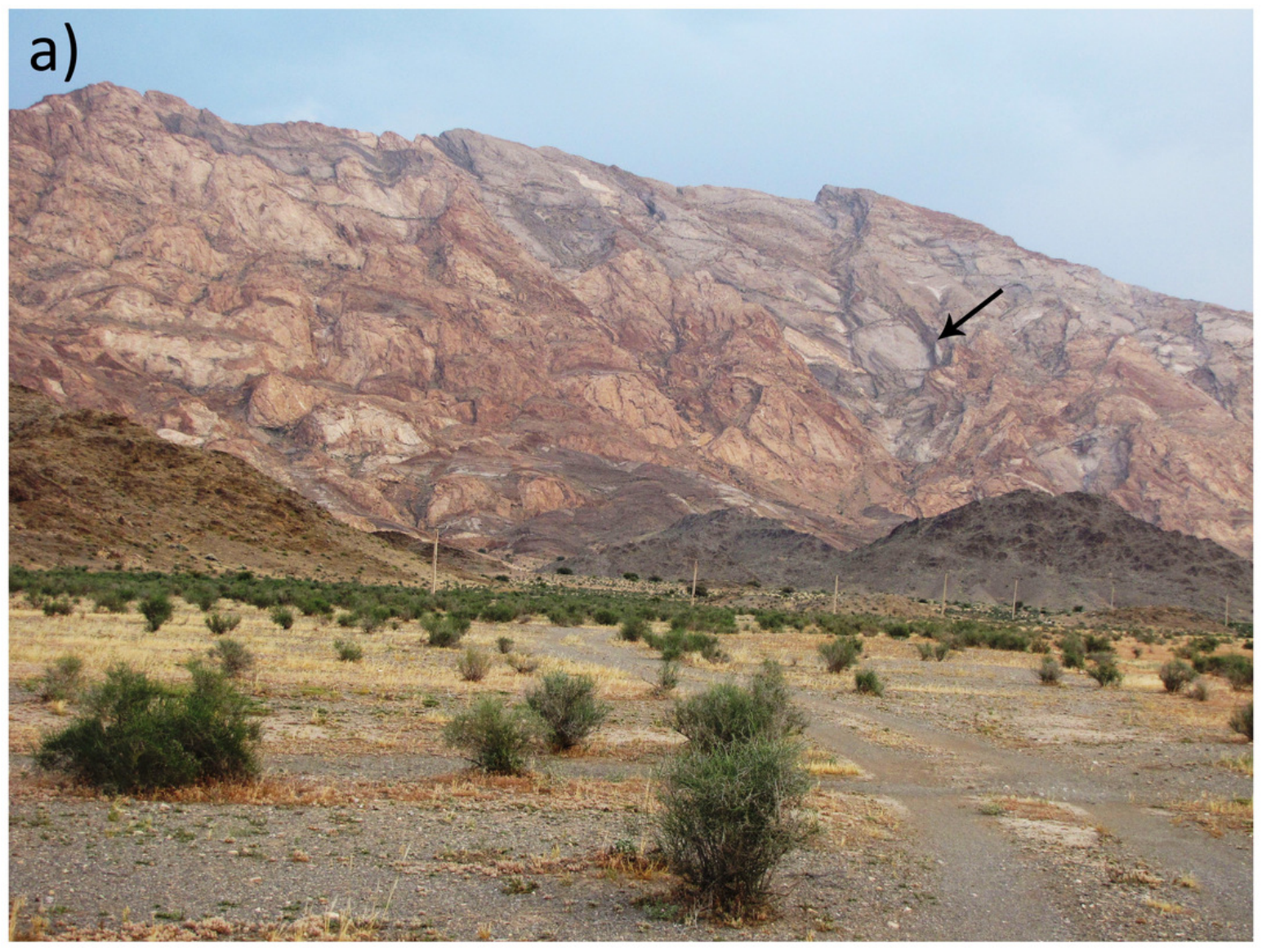

\section{b)}

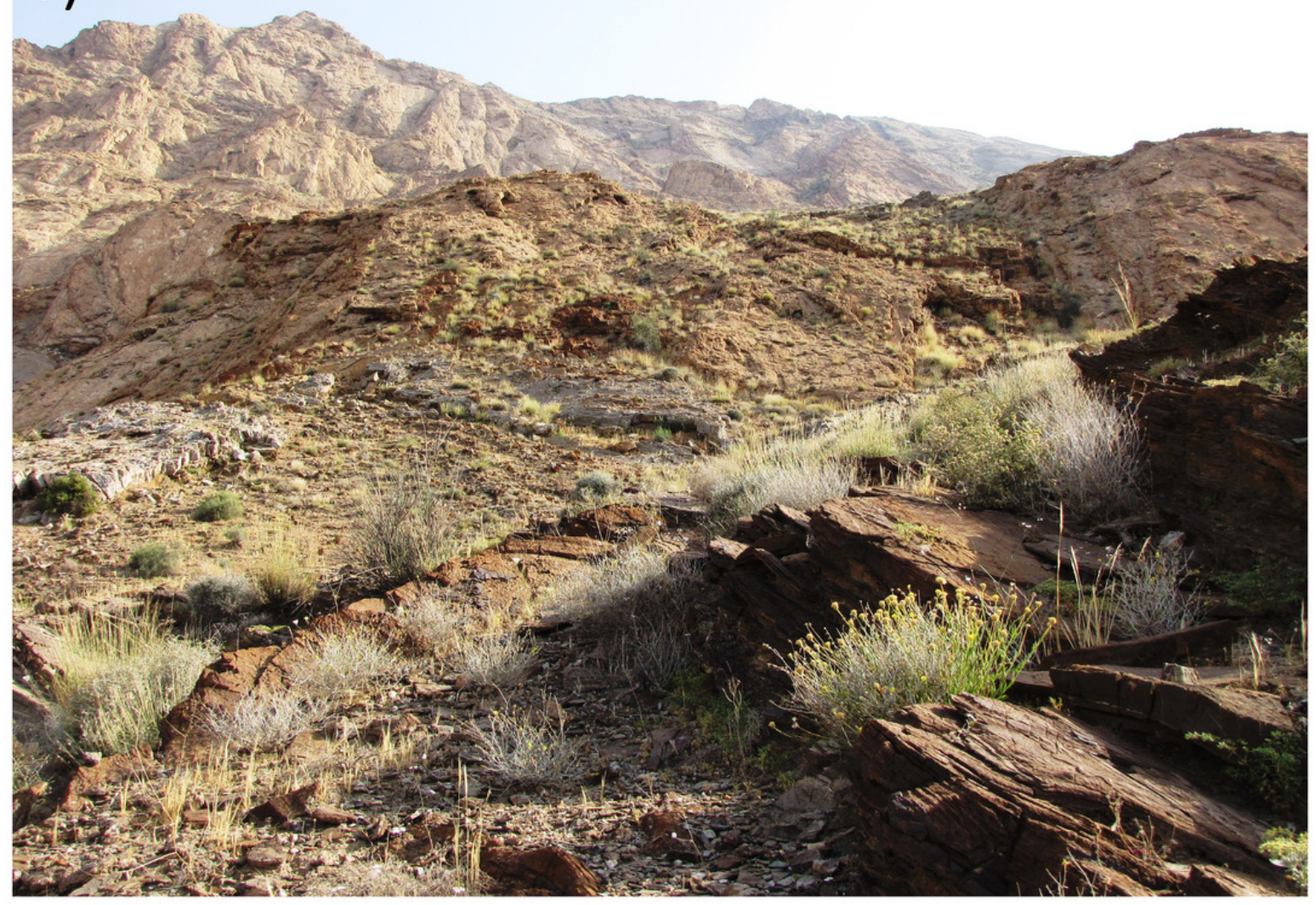


Figure 6

Micro-CT reconstruction of the skull cranial osteology of Dolichophis andreanus comb. nov.

(a) Lateral and (b) dorsal views of the skull. Visualization by Mahdi Rajabizadeh. 

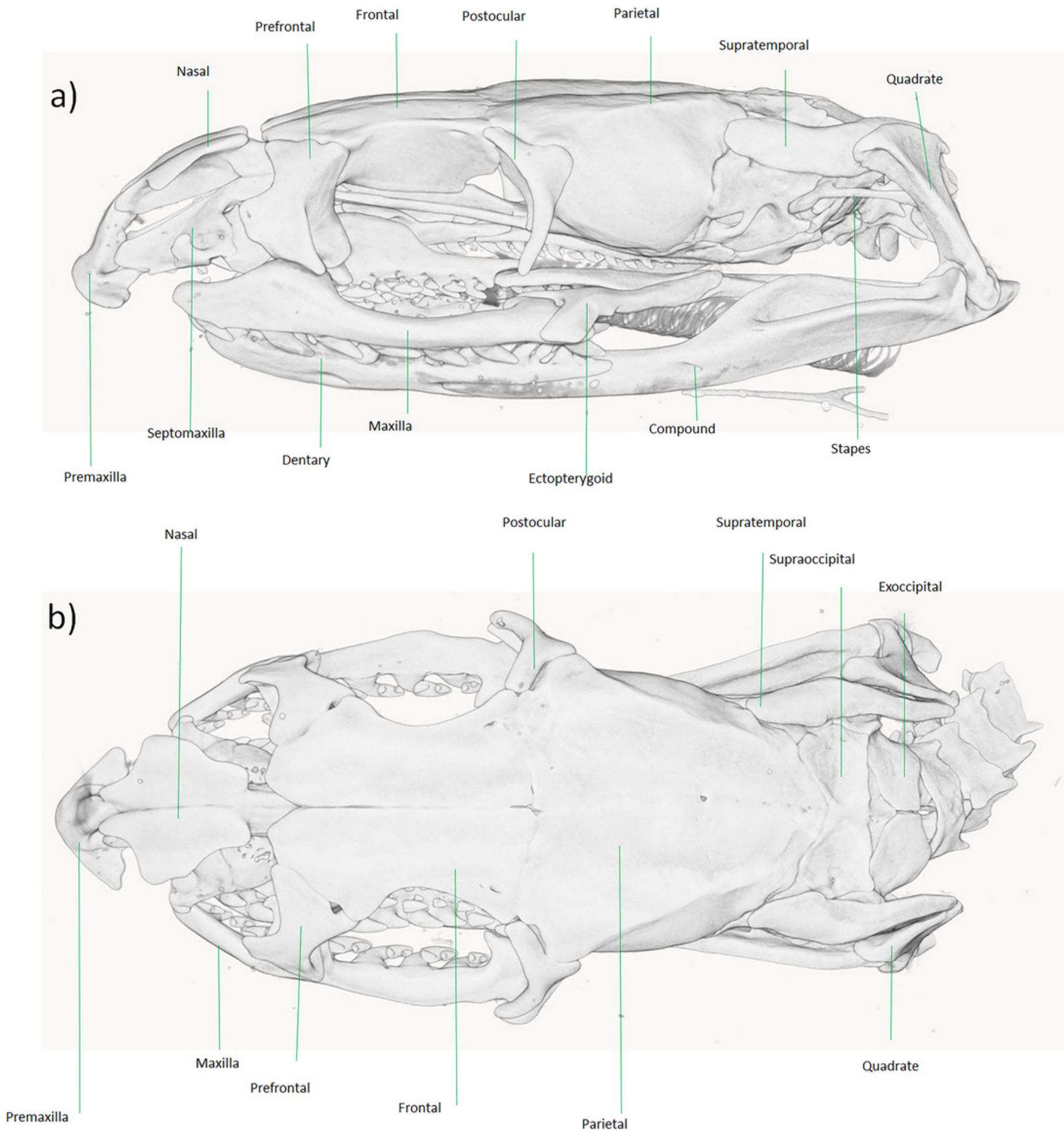